\title{
Enhancing Growth and Yield of Grey Oyster Mushroom (Plearotussajorcaju) Using Different Acoustic Sound Treatments
}

\author{
Roshita Ibrahim ${ }^{1, *}$, Ahmad Azmil Irfan Mohd Jamil ${ }^{1}$, Sayed M. Zain Hasan ${ }^{2}$, Adzemi Mat \\ Arshad $^{2}$, and Zarina Zakaria ${ }^{1}$ \\ ${ }^{1}$ Department of Chemical Engineering Technology, Faculty of Engineering Technology,Universiti \\ Malaysia Perlis (UniMAP), Level 1,Block S2, Campus UnicitiAlam,02100 SgChucuh, Padang Besar, \\ Perlis. \\ ${ }^{2}$ School of Food Science and Technology, Universiti Malaysia Terengganu, 21030 Kuala Terenganu, \\ Terengganu.
}

\begin{abstract}
Mushroom, as believed by many people, grows on specific time and condition as in the wild it grows after a heavy rain falls. The effects of lightning and thunderstorm may suppress the mychorrizal structure to grow and eventually forming fruiting body. This study was conducted to determine the effect of different acoustic sound treatments on the growth and yield of grey oyster mushroom (Pleurotussajor-caju). Five different acoustic sound treatments had been applied during spawning period which were thunder storm, hardcore music, soothing instrumental, Quranic recital and without any sound treatment applied which served as control. The parameters studied were mycelium growth rate, days of mycelium filled up the bags, days of pinhead emergence, days of fruiting body formation, total weight, percentage biological efficiency, pileus color and texture. There were significant differences $(\mathrm{P}<0.05)$ in the mycelium growth among different acoustic sound treatments where sound treated mushroom showed faster growth than control. Similar trend was also observed in yield (total weight and biological efficiency) where there were significant differences $(\mathrm{P}<0.05)$. However, there were no significant differences $(\mathrm{P}>0.05)$ observed in other parameters, such as pinhead emergence, fruiting bodies formation, pileus color and texture. In summary, treatments using different acoustic sound at $75 \mathrm{~dB}$ could be considered as better treatment to enhance the mycelium growth thus accelerate the mushroom cultivation process as well as increasing the mushroom productivity. This research could help farmers to grow and harvest their mushroom at specific time frame and fulfill customer's demand.
\end{abstract}

*Corresponding Author: roshita@unimap.edu.my 


\section{Introduction}

Mushrooms are described as a macro-fungus with large fruiting bodies enough to be seen with naked eye and to be picked by hand [1]. Recently, agricultural field had shown popularity due to advances in the agricultural system technology. Mushroom market in Malaysia had shown high demands mostly caused by increasing in population and the advances in mushroom applications in both medicine and culinary. There are many methods to enhance the growth and yield of mushroom. Sound treatment had been proven to change the cell cycle [2]. This is based on different sound acoustic, sound intensities and sound frequencies. The difference in bio-acoustic sounds shows that mushroom interact with their selective sound waves. Various acoustic sounds were applied in this study which includes rock, soothing instrumental, explosion and religious. The effect of lighting and thunderstorm may encourage the response mechanism for the mushroom to grow and thus, forming fruiting bodies. Mushroom cultivation takes longer time due to its mycelium complicated growth. This affect the growers who tend to give up halfway due to extended cultivation period. Mushroom cultivation is a risky business. It needs a lot of effort and high cost to ensure a hygienic production. A whole mushroom house can be easily contaminated if there are diseases or the presence of outside contaminating agent.

\section{Methodology}

The first step is preparation of substrates. The substrates ingredients are mixed together in the ratio of 1:10:100 of calcium carbonate $\left(\mathrm{CaCO}_{3}\right)$, rice bran and rubber sawdust respectively. The media was ensured to be moist so that it will not disintegrate by adding a little amount of water at about $67 \%$ to $69 \%$. The media of about $500 \mathrm{~g}$ are filled into polyethylene bags. The bags were closed with cotton stuffed caps. The media bags were loaded into the shelf in autoclave followed by sterilization at $121^{\circ} \mathrm{C}$ for 30 minutes. The sterilized media bags were then be removed from autoclave and are allowed to be cooled in the laminar flow for 12 hours before inoculation process. The mushroom culture on corn that are used to inoculate the bags is about $10 \mathrm{~g}$ for each bag. To prevent anycontamination, the inoculation process will be conducted in aseptic way in the laminar flow. The bags were capped and arranged on the rack in the mushroom house for spawning process for 30 to 45 days.

\subsection{Acoustic sound treatment}

In every ten days intervals from the inoculation day, different acoustic sound treatments were applied to the mushroom bags. The mushroom bags were applied with four different acoustic sounds, which are, hardcore music, soothing instrumental, Quranic recital, and thunderstorm effect. Mushroom bags which are not been given any sound treatment were served as control. The reason for not applying the treatment everyday is to give time for the mushroom to rebuild the damaged tissues after the stress applied. The intensity of the sound was measured by using sound level meter ( $\mathrm{dB}$ meter) which was kept constant at $75 \mathrm{~dB}$ at every treatment. The speaker are used to produce different acoustic sounds which are placed in a box together with the mushroom bags so that environmental condition are not being interfered.

\subsection{Spawning stage}

The spawning stage is the growth stage of mushroom mycelium. At this stage, the bags are arranged vertically with the purpose of accelerating of spawning process. Spawning process 
of mycelium takes 30 to 45 days from the date of inoculation to fill up the bags. Temperature, humidity and light are the basic needs for the growth and development of the mushrooms. The appropriate temperature and humidity were maintained at the range of $25-35^{\circ} \mathrm{C}$ and $75-85 \%$ respectively throughout the spawning process. To ensure the level of humidity are sufficient, the floor, wall and bags in the mushroom house were watered daily. Light intensity is only about $30 \%$ during this stage and the mushroom house are protected from dust and pest.

\subsection{Mycelium growth rate}

After the inoculation process are conducted, the mycelium growth rate are determined for every 5 days intervals. The mycelium growth are measured by using ruler in centimeter until the day mycelium filled up the bags (linear length). The mycelium growth rate $(\mathrm{cm} /$ day) are determined for each treatment of acoustic sounds and control.

\subsection{Pin-head emergence}

The cap of mushroom bags were opened to allow the pinhead emergence once mycelium filled up the bags. It takes about 4 to 5 days for the pinhead to emerge from the day the cap opened.

\subsection{Fruiting body formation}

The formation of fruiting body of the oyster mushroom are develop 3 to 5 days after pin-head emergence. The harvesting process required grower to pull the mushroom fruiting bodies from the substrate. After harvesting process done, the bags were closed back with the cap to give the mycelium time to accumulate the nutrient for the next fruiting cycle that takes around 10 to 14 days.

\subsection{Yield of fruiting body}

The fruiting body formation indicates the mushroom can be harvested. By using digital balance, the weight of the fruiting body are weighed. The number of the fruiting bodies were counted and recorded. The mushroom yield are expressed as the biological efficiency (BE) which is the total fresh weight of mushrooms divided by the dry weight of initial substrate.

\subsection{Color analysis}

The determination of the color properties of mushroom fruiting bodies are done with Minolta Chromometer using CIELAB Color parameter, $L^{*}, a^{*}, b^{*}$. Three different points from the same surface of mushroom pileus were taken. The $\mathrm{L}^{*}, \mathrm{a}^{*}, \mathrm{~b}^{*}$ value were recorded. The $\mathrm{L}$ means monochrome scale expressing the amount of reflected light. $\mathrm{L}$ of 100 means pure white while $L$ of 0 is matt black. There are two scales of colors, which are ' $a$ ' is red to green and ' $b$ ' is yellow to blue.

\subsection{Texture analysis}

The firmness of the mushrooms are measured by using texture analyzer TA.XTplus. Firstly, the sample are placed on the stage of texture analyzer. Probe $\mathrm{P} / 2$ are used to penetrate the 
samples at predetermined distance. Penetration test using $2 \mathrm{~mm}$ diameter probe are applied to puncture the mushroom cap from the top to a $5 \mathrm{~mm}$ depth. Texture Expert Software showed the texture profile of the penetration which include force, distance and time during the analysis process conducted. The maximum compression force are recorded.

\subsection{Pileus diameter}

By using a ruler, the diameter of fruiting body are taken. For each mushrooms that were harvested from the mushroom bags, the largest mushroom and the smallest mushroom were choosen for diameter measurement. The range of measurement are from each end side of the mushroom's pileus. The measurements were recorded.

\subsection{Experimental design and statistical analysis}

The experiment are designed based on Complete Randomized Design (CRD) with a control and 4 different acoustic sounds. Each treatment were having five replicates. The statistical analysis used are SAS version 16.0. The differences among the treatments were analyzed using one-way Analysis of Variance (ANOVA), considering significant at $(\mathrm{P}<0.05)$ using Tukey test.

\section{Results and discussion}

This section details out the results obtained and the discussion on the mycelium growth rate, the number of days taken for the mycelium to fill-up-the bag, pinhead emergence and fruiting bodies formation as well as the yield and the physical properties of the fruiting bodies harvested.

\subsection{Mycelium growth rate}

The result of mycelium growth rate on different sound treatment was presented in Figure 1. The graph shows that there were significant differences $(\mathrm{P}<0.05)$ among days of treatment. All the treated bags showed a faster mycelium growth compared to control. The fastest rate of mycelium reached $18.5 \mathrm{~cm}$ was when treated with thunder storm ( 28 days). The slowest rate of mycelium fill up the bags was when there is no sound treatment given to the bags (control). Control took 37 days to reach $18.5 \mathrm{~cm}$. On the other hand, the treatment using hardcore music, soothing instrumental and quranic recital shared almost the same days of mycelium to reach $18.5 \mathrm{~cm}$ (30 days). 


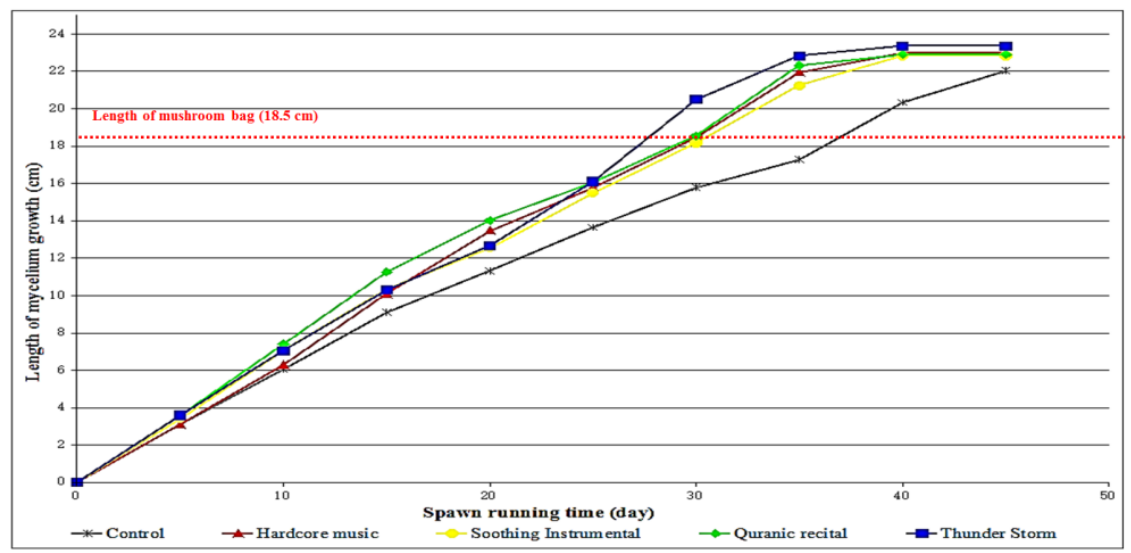

Fig. 1. The growth of mycelium subjected to different acoustic sound treatments during spawn running period.

Based on a research of mushroom growth using physical treatment which is done by [3], it was reported that control treatment took the longest time of 40.6 days to complete the spawning of $16 \mathrm{~cm}$ length of the mushroom bag. Faster spawning time were observed by other physically treated bags where high sound intensity treatment only took 23.6 days followed by bright light treatment which took 23.8 days, cold temperature treatment which took 24.2 days and electrical shock treatment which took 25.8 days [3]. All mushrooms species exhibited different mushroom growth pattern while $P$. sajorcaju showed a growth rate of $1.2 \mathrm{~cm} /$ day [4].He had also reported that there were significant effects of music on the germination of seeds when compared to untreated control plants.

\subsection{Days of mycelium fill-up the bag, pinhead emergence and fruiting bodies formation}

There were significant different $(\mathrm{P}<0.05)$ in the number of days taken for mycelium to filled up the bags among all the treatments (Figure 2). Sound treated bags show slightly shorter time compared to control, where thunder storm took 34 days followed by quranic recital (35 days), soothing instrumental (36 days) and hardcore music (37 days). Meanwhile, control took the longest time which is 42 days. However, there were no significant different $(\mathrm{P}>0.05)$ in pinhead emergence among different sound treatment. The time recorded for pinhead emergence are 3 to 5 days for sound treated bags, whereas for control it took 8 days for pinhead emergence. Pinhead emergence is an important factor in mushroom cultivation which indicate the initial stage of fruiting bodies formation. There were also no significant different $(\mathrm{P}>0.05)$ in fruiting bodies formation among different sound treatment. The time recorded for fruiting bodies formation are 8 days for sound treatment, and 9 days for control. Days for fruiting bodies formation was counted from the pinhead emergence until the mushroom pileus had properly developed. 


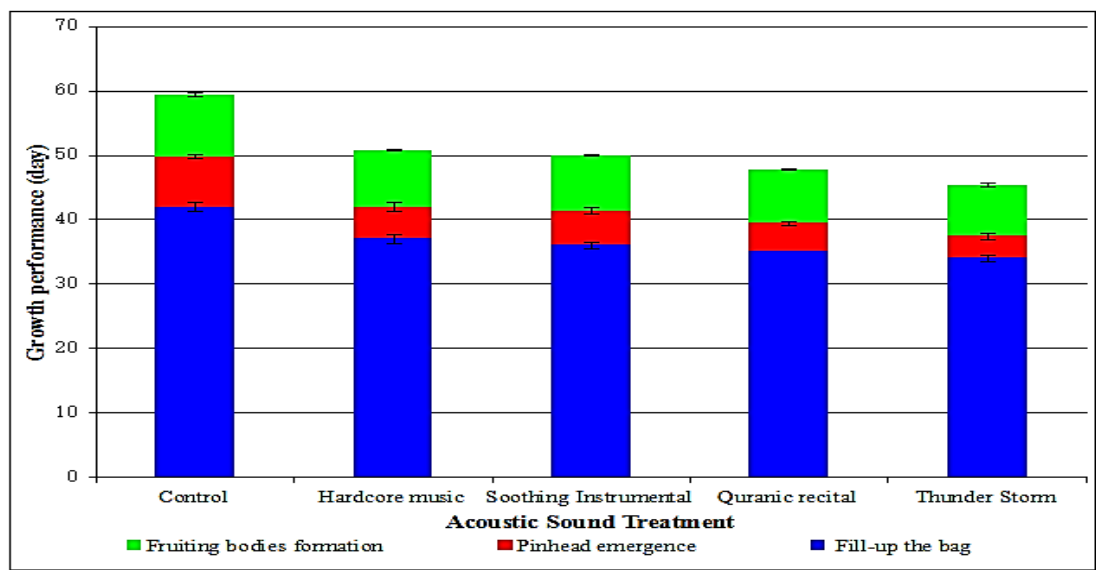

Fig. 2. The growth performance of grey oyster mushroom subjected to different sound treatments. Vertical bars represent standard errors.

A study that were done by [5] showed that there were significant different $(\mathrm{P}<0.05)$ in the number of days for mycelium to filled-up the bags among different sound intensity treatment. Based on his study, treatment with $65 \mathrm{~dB}$ and $75 \mathrm{~dB}$ showed significantly shorter time (36 days) followed by $85 \mathrm{~dB}$ and $95 \mathrm{~dB}$ (38 days), whereas for control $(0 \mathrm{~dB})$, it took the longest time (48 days). According to [6], sound waves may increase the quality of crops including mushrooms.

However, the result for mycelium to filled-up the bags in this study was relatively longer as compared to the result obtained from the study done by Shah et al. (2004) and Mondalet al. (2010) which only took 21 to 24 days. The slower growth of mycelium in this study is might due to the high temperature and low relative humidity in the mushroom house as compared to the ideal temperature and relative humidity for mushroom house (temperature : $28-30^{\circ} \mathrm{C}$, relative humidity : $80-85 \%$ ). The study done by [5] also showed that there were no significant differences $(\mathrm{P}>0.05)$ for pinhead emergence and fruiting bodies formation among different sound intensity treatment. The time recorded for pinhead emergence and fruiting bodies formation in his study were 3 to 4 days and 6 to 7 days respectively. A study done by [9] had reported that pinhead emergence appeared 5 days after spawning period. Meanwhile, the fruiting bodies formation recorded in this study was slower than the one reported by [8] which only took 2 to 3 days. The insignificant differences $(\mathrm{P}>0.05)$ for pinhead emergence and fruiting bodies formation is might due to the same mushroom species.

\subsection{Yield}

For total weight of fruiting bodies, there were significant differences $(\mathrm{P}<0.05)$ among all the treatments (Table 1). Treatment with hardcore music tends to show the highest yield (342.34 $\mathrm{g})$, followed by thunder storm (313.23 g), soothing instrumental $(299.92 \mathrm{~g})$ and quranicrecital $(281.89 \mathrm{~g})$. For control, it has the lowest yield which is only $147.54 \mathrm{~g}$. For percentage of biological efficiency, the graph pattern is exactly the same as total weight (Table 1). Treatment with hardcore music shows the highest biological efficiency $(68.47 \%)$, followed by thunder storm (62.65\%), soothing instrumental $(59.98 \%)$ and quranic recital $(56.38 \%)$. For control, it has the lowest biological efficiency which is only $29.51 \%$. 
Table 1. The mean values for yield (total weight and biological efficiency) of grey oyster mushroom.

\begin{tabular}{|c|c|c|}
\hline Acoustic Sound Treatments & Total Weight (g) & Biological Efficiency (\%) \\
\hline Control & $147.54 \pm 44.69^{\mathrm{b}}$ & $29.51 \pm 8.94^{\mathrm{b}}$ \\
\hline Hardcore Music & $342.34 \pm 48.40^{\mathrm{a}}$ & $68.47 \pm 9.68^{\mathrm{a}}$ \\
\hline Soothing Instrumental & $299.92 \pm 34.59^{\mathrm{a}}$ & $59.98 \pm 6.92^{\mathrm{a}}$ \\
\hline Quranic Recital & $281.89 \pm 50.57^{\mathrm{a}}$ & $56.38 \pm 10.11^{\mathrm{a}}$ \\
\hline Thunder Storm & $313.23 \pm 29.61^{\mathrm{a}}$ & $62.65 \pm 5.99^{\mathrm{a}}$ \\
\hline
\end{tabular}

Note : Values are means of 5 replicates. Means $(\mathrm{n}=5) \pm$ standard deviation.

$a-b$ : Values bearing the same superscript within the same column are not significant at $5 \%$ level $(\mathrm{P}>0.05)$.

Houand Mooneyham(1999)[6]had investigated the effect of Agri-wave technology on the plant meridian system to improve the yield and quality of plants. From his investigation, sound waves at frequencies of $0.1 \mathrm{kHz}$ to $1 \mathrm{kHz}$ and intensity of $70 \mathrm{~dB}$ for 3 hours from Plant Acoustic Frequency Technology (PAFT) generator significantly increased the yield of sweet pepper, cucumber and tomato by $30.05 \%, 37.10 \%$ and $13.20 \%$ respectively. Furthermore, the yield of lettuce, spinach, cotton, rice and wheat were increased by $19.60 \%, 22.70 \%$, $11.40 \%, 5.70 \%$, and $17.00 \%$ respectively. The audio treatment also increased the yield of edible mushrooms from $8.00 \%$ to $15.80 \%$ and also increased the fruit size from $2.40 \%$ to $43.30 \%$ respectively [6]. According to Royse et al. (2008), biological efficiency was determined by the ratio of fresh mushroom harvested per weight of dry substrate expressed in percentage. The study done by [5] had reported that for percentage of biological efficiency, there was no significant different $(\mathrm{P}>0.05)$ among all the sound intensity treatment. By comparing to this study, it shows that different type of acoustic sound treatment can produce different yield of grey oyster mushroom.

\subsection{Physical properties}

No significant differences $(\mathrm{P}>0.05)$ was observed in $\mathrm{L}^{*}, \mathrm{a}^{*}$ and $\mathrm{b}^{*}$ values among different sound treatment (Table 2). For $\mathrm{L}^{*}$ value that indicates light intensity, all treatments show almost the same value (52.89-53.99). For $\mathrm{a}^{*}$ value that indicates red to green color, all treatments show almost the same value (7.09-7.73).For $b^{*}$ value that indicates yellow to blue color, all treatments show almost the same value (9.87-11.38). There was no significant different $(\mathrm{P}>0.05)$ for the firmness of pileus among all the treatments (Table 2). The firmness values were in the range of $13.55 \mathrm{~g}$ to $15.00 \mathrm{~g}$. Based on the study done by [5], there was no significant different $(\mathrm{P}>0.05)$ for the firmness of Pleurotussajor-caju among different sound intensity treatment, which the values were in the range of $117.31 \mathrm{~g}$ to $107.24 \mathrm{~g}$. [3] also reported that there was no significant different $(\mathrm{P}>0.05)$ for the firmness of grey oyster mushroom among different physical treatment, which the values were in the range of $77.69 \mathrm{~g}$ to $61.19 \mathrm{~g}$. The similarities of the firmness is might probably due to the same species of grey oyster mushroom that was used in this study. 
Table 2. The mean values for physical properties (color and firmness) of grey oyster mushroom.

\begin{tabular}{|c|c|c|c|c|}
\hline \multirow{2}{*}{$\begin{array}{c}\text { Acoustic Sound } \\
\text { Treatments }\end{array}$} & \multicolumn{3}{|c|}{ Pileus Color } & \multirow{2}{*}{ Firmness (g) } \\
\cline { 2 - 5 } & ${\text { Color } \mathbf{L}^{*}}^{\text {Color } \mathbf{a}^{*}}$ & Color b $^{*}$ & \\
\hline Control & $52.89 \pm 8.01^{\mathrm{a}}$ & $7.62 \pm 0.62^{\mathrm{a}}$ & $10.57 \pm 1.94^{\mathrm{a}}$ & $13.89 \pm 2.71^{\mathrm{a}}$ \\
\hline Hardcore Music & $53.16 \pm 1.88^{\mathrm{a}}$ & $7.29 \pm 1.48^{\mathrm{a}}$ & $11.38 \pm 1.18^{\mathrm{a}}$ & $14.22 \pm 2.90^{\mathrm{a}}$ \\
\hline Soothing & $53.99 \pm 1.92^{\mathrm{a}}$ & $7.73 \pm 0.51^{\mathrm{a}}$ & $9.87 \pm 0.73^{\mathrm{a}}$ & $13 . \pm 2.18^{\mathrm{a}}$ \\
\hline Quranic Recital & $53.85 \pm 3.27^{\mathrm{a}}$ & $7.28 \pm 0.32^{\mathrm{a}}$ & $10.13 \pm 0.68^{\mathrm{a}}$ & $14.89 \pm 3.06^{\mathrm{a}}$ \\
\hline Thunder Storm & $53.69 \pm 1.59^{\mathrm{a}}$ & $7.09 \pm 0.64^{\mathrm{a}}$ & $9.89 \pm 1.32^{\mathrm{a}}$ & $15.00 \pm 3.04^{\mathrm{a}}$ \\
\hline
\end{tabular}

Note : Values are means of 6 replicates. Means $(n=6) \pm$ standard deviation.

$\mathrm{a}-\mathrm{b}$ : Values bearing the same superscript within the same column are not significant at $5 \%$ level $(\mathrm{P}>0.05)$.

Color L* value represent the lightness of the color which range from 0 (black) to 100 (white), the $\mathrm{a}^{*}$ value which range from -60 (green) to +60 (red), and the $\mathrm{b}^{*}$ value which range from -60 (blue) and +60 (yellow) [3]. According to [5], no significant differences $(\mathrm{P}>0.05)$ were observed in $\mathrm{L}^{*}, \mathrm{a}^{*}$ and $\mathrm{b}^{*}$ values among different sound intensity treatment. The $\mathrm{L}^{*}$ value obtained by [5] was in between 49.61 to 59.70 which is almost similar to the value reported by [3] which is 59.17. According to [3], the $\mathrm{a}^{*}$ and $\mathrm{b}^{*}$ values from mushroom cultivated through wood shaving was 7.79 and 9.84 respectively. The $b^{*}$ value that was also obtained by [5] had showed darker color which was 14.08 compared to this study which is in the range of 9.87 to 11.38 . Firmness was defined as the force needed to break or penetrate the flesh. There were a huge differences of firmness values between this study and the study done by [5] and [3]. The reason is because of the condition of the grey oyster mushroom that were used in the firmness test. Firstly, the harvested mushrooms from the mushroom house were already aged. Secondly, all the mushroom's pileus were wet and slippery due to refrigerated storage. Both of these reasons had affected the firmness values of the mushrooms, and the real firmness value of grey oyster mushroom (Pleurotussajor-caju) could not be obtained.

\section{Summary}

In this study, there were significant differences $(\mathrm{P}<0.05)$ in the growth and yield of grey oyster mushroom treated with different acoustic sounds which were thunder storm, hardcore music, soothing instrumental and quranic recital. Each parameter shows differences in parameters analyzed. For example, treatment with thunder storm resulted in the best enhancement for the mycelium growth. Whereas, treatment with hardcore music was the best sound to enhance the yield of grey oyster mushroom. However, there were no significant differences $(\mathrm{P}>0.05)$ in other parameters. All the sound treatments did not show any differences in the number of days taken for pinhead emergence, fruiting body formation, as well as in the color and texture properties. Based on the results, it can be concluded that acoustic sound treatment could enhance the growth and yield of grey oyster mushroom, and each of different acoustic sound types have their own enhancement capabilities.

The authors would like to acknowledge all the staffs in the Department of Chemical Engineering Technology,UniMAPfor their helps and support. 


\section{References}

1 S.T. Chang, P. Miles, Mycologist 6, 64 (1992)

2 B.C. Wang, A. Sakanishi, Colloid Surface B, 12, 89 (1998)

3 R. Ibrahim, K.M. Aziz, A.M. Arshad, S.M. Zain, Malays. Appl. Biol., 44, 67 (2015)

4 K. Creath, G.E. Schwartz, J. Alt. Comp. Med., 10, 113 (2004)

5 S.M. Firdaus, A.R. ShamsulBahri, M. Rahijan, AbdWahab A. Rahman, M. Rohana, R. Ibrahim, Advances in Life Science and Technology, 28 (2015)

6 T.Z. Hou, R.E. Mooneyham, Am. J. Chin. Med., 27, 1 (1999)

7 R. Gush, Mushworld, Oyster Mushroom Cultivation (Mushroom Growers Handbook, 2004)

8 M. Dahmardeh, R. Hossienabadi, H. Safarpoor, J. Food Agri. Environ., 8, 996 (2010)

9 S.R. Mondal, M.J. Rehana, M.S. Noman, S.K. Adhikary, Comparative study on growth and yield performance of oyster mushroom (Pleurotusflorida) on different substrates (Agrotechnology Discipline, Khulna University, Bangladesh 2010) 